\title{
Severe infusion reactions to tocilizumab in young children with systemic juvenile idiopathic arthritis
}

Objective: Tocilizumab (TCZ) is the first-line agent against systemic juvenile idiopathic arthritis (sJlA) refractory to glucocorticoids. However, some patients discontinue TCZ because of severe infusion reactions (IRs). This study aimed to demonstrate the characteristics of patients with sJlA who develop severe IRs to TCZ, and investigate its risk factors.

Method: Thirty-one patients with newly diagnosed SJIA (boys-16; girls-15) who received at least one infusion of TCZ were enrolled.

Results: Four patients presented with TCZ-induced severe IRs. IRs appeared in the early phase of treatment, especially within the 10th infusion of TCZ. All of these patients were girls (IR group vs. non-IR group, $p=0.043$ ) and younger than 3 years old. The median age at initiation of TCZ in the IR group was significantly younger than that in the non-IR group $(p=0.001)$. At disease onset, more patients in the IR group (75\%) were complicated by macrophage activation syndrome than those in the non-IR group $(11 \%, p=0.016)$. The dose of TCZ per kg was not different between the groups. However, the dose per $\mathrm{m}^{2}$ was less in the IR group than in the non-IR group ( $\left.212 \mathrm{vs.} 252 \mathrm{mg} / \mathrm{m}^{2}, \mathrm{p}=0.052\right)$. In the IR group, except for one patient, anti-TCZ IgG and/or anti-TCZ IgE antibodies were detected.

Conclusions: Risk factors of TCZ-induced severe IRs are female sex, age younger than 3 years old, and onset with macrophage activation syndrome. An optimal regimen of induction of remission with TCZ in such patients should be established.

Keywords: children • infusion reaction • interleukin- 6 • systemic juvenile idiopathic arthritis • tocilizumab

\section{Introduction}

Systemic juvenile idiopathic arthritis (sJIA) is a chronic inflammatory disease, characterized by remittent fever, rheumatoid rash, and arthritis [1]. During the clinical course of sJIA, approximately $7 \%$ of patients suffer from macrophage activation syndrome (MAS), which can be life-threatening [2,3]. Although glucocorticoids (GCs) have been the mainstay of treatment against sJIA, $45-66 \%$ of patients take a refractory course and require long-term treatment with GCs [4-6]. However, since the introduction of biologics, outcomes of such difficult patients have greatly improved. Tocilizumab (TCZ), a humanized anti-interleukin (IL)-6 receptor monoclonal antibody, can inhibit IL-6 from binding to its receptor and block signal transduction of IL-6 through gp130, which suppresses the inflammatory response $[7,8]$.

Although TCZ is efficacious and generally well tolerated in patients with refractory sJIA, unfortunately, some patients need to have TCZ treatment discontinued because of serious infections or other adverse events. Similar to other biologics, anti-drug antibodies (ADAs) develop a reduced therapeutic response and immediate or delayed hypersensitivity. Biologicinduced hypersensitivity is mostly immediate infusion reactions (IRs), which occur during or within 1 hour after starting infusion, frequently resulting in discontinuation of the agents. Some previous studies have reported such a clinical issue associated with anti-TCZ antibodies in patients with rheumatoid arthritis $[9,10]$, but there have been no reports in patients with sJIA. Therefore, this study aimed to demonstrate the characteristics of patients with sJIA who develop severe IRs to TCZ, and investigate its risk factors.

\section{Methods}

Patients

We performed a retrospective review of

\section{Tomo Nozawa*, Kenichi Nishimura, Takashi Ohya, Asami Oohara, Ryoki Hara \& Shuichi Ito Department of Pediatrics, Graduate School of Medicine, Yokohama City University, Kanagawa, Japan}

*Author for correspondence: tnozawa@yokohama-cu.ac.jp 
electronic medical charts of 42 patients ( 21 boys and 21 girls, with a median age at diagnosis of 6.0 years; range, $0.5-15.8$ years) who were initially diagnosed with sJIA from April 2008 to April 2015 in our institute. Thirty-one of the 42 patients ( 16 boys and 15 girls, with a median age at diagnosis of 6.5 years; range, $0.5-14.3$ years) received at least one infusion of TCZ because of resistance to conventional therapy, such as difficulty of induction of remission, high-dose corticosteroid dependency, and relapse. In 31 patients, the median age at onset of sJIA and at the first infusion of TCZ was 6.5 years (range, 0.5-14.2 years) and 7.2 years (range, 1.1-14.3 years), respectively. Four of 31 patients developed severe IRs to TCZ infusion. This study was conducted in accordance with the ethical standards of the Declaration of Helsinki and approved by the Medical Ethical Committee of Yokohama City University. All patients and parents provided written informed consent.

Definitions of infusion reactions and their severity

IRs was defined as any adverse events that developed within 24 hours of TCZ infusion, including allergic reactions. IRs was also subdivided according to signs and symptoms into mild, moderate, or severe by physicians. Mild or moderate reactions were defined as those that were self-limiting and resolved spontaneously after temporary cessation of infusion and reduction of infusion speed. Severe IRs were defined as reactions that could potentially cause death or permanent disabilities, and required discontinuation of TCZ and prompt treatment with antihistamine and hydrocortisone. Severe reactions, included hypotension and respiratory distress, such as wheeze and tachypnea, with or without severe urticaria.

\section{Clinical Data}

We investigated clinical data, including sex, age at diagnosis with sJIA, age at TCZ initiation, duration from diagnosis to TCZ initiation, dose of TCZ $\left(\mathrm{mg} / \mathrm{kg}\right.$ and $\left.\mathrm{mg} / \mathrm{m}^{2}\right)$, dose of prednisolone (or equivalent) at initiation of TCZ, concomitant immunosuppressive drugs, history of allergies, history of drug allergies, MAS at an onset of sJIA, and laboratory data at initiation of TCZ. Laboratory data included the white blood cell (WBC) count, hemoglobin (Hb) levels, hematocrit, platelet count, and levels of alanine aminotransferase, C-reactive protein (CRP), albumin, ferritin, IL-6, IL-18, and immunoglobulin-E (IgE). Anti-TCZ IgE and anti-TCZ IgG antibodies were examined in all patients who were complicated by severe IRs.

\section{Statistical Analysis}

Values are presented as median and range for continuous data, and as proportions for categorical data. Fisher's exact test was used for comparison of categorical data and the MannWhitney $U$ test was used for comparison of continuous data. Statistical significance was defined for values of $\mathrm{p}<0.05$. All statistical analyses were performed using IBM SPSS Statistics version 23.0 software (IBM, Armonk, NY)

\section{Results}

\section{Baseline characteristics}

The patients' demographic and clinical features in the IR group ( $n=4)$ and non-IR group $(n=27)$ are shown in Table 1 . The proportion of girls in the IR group (100\%) was significantly higher than that in the non-IR group $(41 \%, \mathrm{p}=0.043)$. The median age at diagnosis of sJIA and the median age at initiation of TCZ in the IR group were significantly younger than those in the nonIR group ( $\mathrm{p}=0.002$ and $\mathrm{p}=0.001$, respectively). No significant difference in the dose of TCZ $(\mathrm{mg} / \mathrm{kg})$ was observed between the two groups, but the TCZ dose in $\mathrm{mg} / \mathrm{m}^{2}$ in the IR group tended to be lower than that in the non-IR group $(\mathrm{p}=0.052)$. There were no significant differences in the history of allergies and drug allergies between the two groups. The proportion of occurrence of MAS at an onset of sJIA was significantly higher in the IR group than in the non-IR group ( $\mathrm{p}=0.016$, Table 2$)$.

With regard to laboratory examinations, the proportion of CRP levels $>0.05 \mathrm{mg} / \mathrm{dL}$ at 4 weeks after initiation of TCZ was significantly higher in the IR group than in the non-IR group $(\mathrm{p}=0.002)$.

Serum IL-18 levels tended to be higher in the IR group than in the non-IR group (median, $70,979 \mathrm{pg} / \mathrm{mL}$ vs $15,921 \mathrm{pg} / \mathrm{mL}, \mathrm{p}=0.076)$. Additionally, anemia was significantly more severe in the IR group than in the non-IR group $(\mathrm{Hb} ; \mathrm{p}=0.027$, hematocrit; $\mathrm{p}=0.013$, Table 2)

\section{Clinical courses and outcomes of four} patients with severe IRs due to TCZ

The clinical courses of four patients with severe IRs are shown in Table 3. Severe IRs appeared in the early phase of treatment, especially within the 10th infusion of TCZ. Anti-TCZ IgG and IgE 


\begin{tabular}{|c|c|c|c|}
\hline Variables & $\begin{array}{c}\text { Anaphylaxis group } \\
(n=4)\end{array}$ & $\begin{array}{l}\text { Non-anaphylaxis } \\
\text { group }(n=27)\end{array}$ & $\mathbf{p}$ \\
\hline Sex (male, female) & 0,4 & 16,11 & $0.043^{*}$ \\
\hline Age at diagnosis of sJlA (years) & $1.9(0.5-2.8)$ & $7.1(2.3-14.3)$ & $0.002^{*}$ \\
\hline Age at TCZ initiation (years) & $2.3(1.1-2.8)$ & $7.3(3.2-14.3)$ & $0.001^{*}$ \\
\hline Duration from diagnosis to TCZ initiation (years) & $0.4(0.1-0.6)$ & $0.3(0.0-2.2)$ & 0.61 \\
\hline Dose of TCZ $(\mathrm{mg} / \mathrm{kg})$ & $9.2(8.0-11.4)$ & $9.3(6.4-10.4)$ & 0.48 \\
\hline Dose of TCZ $\left(\mathrm{mg} / \mathrm{m}^{2}\right)$ & $212(164-250)$ & $252(162-332)$ & 0.052 \\
\hline $\begin{array}{l}\text { Dose of PSL (or equivalent) at TCZ initiation ( } \mathrm{mg} / \mathrm{kg} / \\
\text { day) }\end{array}$ & $1.54(0.57-2.09)$ & $0.81(0.11-2.19)$ & 0.2 \\
\hline Concomitant immunosuppressive drugs, $\mathrm{n}$ & 0 & MTX 2, СуA 1 & \\
\hline History of allergy, $n(\%)$ & $0(0)$ & $9(33)$ & 0.3 \\
\hline History of drug allergy, $\mathrm{n}(\%)$ & $1(25)$ & $2(8)$ & 0.35 \\
\hline MAS at onset of $s J \mid A, n(\%)$ & $3(75)$ & $3(11)$ & $0.016^{*}$ \\
\hline \multicolumn{4}{|c|}{$\begin{array}{l}\text { sJIA, systemic juvenile idiopathic arthritis; TCZ, tocilizumab; PSL, prednisolone; MTX, methotrexate; CyA, } \\
\text { cyclosporine; } \\
\text { MAS, macrophage activation syndrome. } \\
{ }^{*} \text { significant at } p<0.05 \text {. }\end{array}$} \\
\hline
\end{tabular}

\begin{tabular}{|c|c|c|c|c|}
\hline \multicolumn{2}{|c|}{ Variables } & Anaphylaxis group $(n=4)$ & $\begin{array}{c}\text { Non-anaphylaxis negative } \\
\text { group }(n=27)\end{array}$ & $\mathbf{p}$ \\
\hline \multicolumn{5}{|c|}{ Laboratory data at TCZ initiation } \\
\hline WBC count & $(/ \mu \mathrm{L})$ & $30,400(11,500-57,800)$ & $17,500(5,700-44,200)$ & 0.77 \\
\hline $\mathrm{Hb}$ & (g/dL) & $9.1(8.6-9.3)$ & $11.5(8.8-14.4)$ & $0.027^{*}$ \\
\hline Hct & $(\%)$ & $27.6(27.1-29.8)$ & $34.5(27.5-41.6)$ & $0.013^{*}$ \\
\hline Plt & $\left(\times 10^{4} / \mu \mathrm{L}\right)$ & $58.2(43.7-70.1)$ & $39.3(16.2-72.7)$ & 0.099 \\
\hline ALT & $(\mathrm{U} / \mathrm{L})$ & $37(36-79)$ & $18(8-157)$ & 0.1 \\
\hline CRP & $(\mathrm{mg} / \mathrm{dL})$ & $3.32(0.03-8.24)$ & $1.81(0.01-9.61)$ & 0.75 \\
\hline Alb & $(g / d L)$ & $3.5(3.1-4.0)$ & $3.6(2.5-4.5)$ & 0.81 \\
\hline Ferritin & $(\mathrm{ng} / \mathrm{mL})$ & $85(21-445)$ & $106(2-4,566)$ & 0.56 \\
\hline IL-6 & $(\mathrm{pg} / \mathrm{mL})$ & $6.2(1.6-255.6)$ & $16.0(1.1-152.0)$ & 0.49 \\
\hline IL-18 & $(\mathrm{pg} / \mathrm{mL})$ & $70,979(64,200-80,285)$ & $15,921(357-167,265)$ & 0.076 \\
\hline $\lg \mathrm{E}$ & $(\mathrm{U} / \mathrm{mL})$ & $211(70-261)$ & $141(4-2,534)$ & 0.73 \\
\hline $\mathrm{CRP}>0.05 \mathrm{mg} / \mathrm{dL}$ & & $4(100)$ & $4(15)$ & $0.002^{*}$ \\
\hline \multicolumn{5}{|c|}{ at 4 weeks after TCZ initiation, $\mathrm{n}(\%)$} \\
\hline \multicolumn{5}{|c|}{$\begin{array}{l}\text { TCZ, tocilizumab; WBC, white blood cell; Hb, hemoglobin; Hct, hematocrit; Plt, platelet count; ALT, alanine } \\
\text { aminotransferase; CRP, C-reactive protein; } \\
\text { Alb, albumin; IL-6, interleukin-6 (normal range: }<4 \mathrm{pg} / \mathrm{mL} \text { ); IL-18, interleukin- } 18 \text { (normal range: }<500 \mathrm{pg} / \mathrm{mL} \text { ); lgE, } \\
\text { immunoglobulin-E. } \\
\text { *significant at } \mathrm{p}<0.05 \text {. }\end{array}$} \\
\hline
\end{tabular}

antibodies were detected in one patient (Patient 2). Anti-TCZ IgG and anti-TCZ IgE antibodies were detected in one patient each (Patient 1 and Patient 4). Although one patient (Patient 3) did not show anti-TCZ antibodies, her serum concentration of TCZ decreased to undetectable levels, even after repeated TCZ infusions. Only Patient 4 was able to continue TCZ administration, despite the appearance of antiTCZ IgE antibody. Under frequent monitoring of serum levels of CRP, which is a surrogate marker of efficacy of TCZ, TCZ was successfully administered to Patient 4 in conjunction with antihistamine and hydrocortisone. Finally, all four patients required a high dose of GCs, and consequently developed severe adverse effects from GCs, such as growth impairment. Furthermore, GC-induced glaucoma and a cataract occurred in one patient, and she needed to have two operations.

\section{Discussion}

To the best of our knowledge, this is the first report to investigate characteristics of patients with sJIA who developed severe IRs to TCZ and their risk factors. During the last decades, various biologics have been developed, and these have dramatically improved the outcome 


\begin{tabular}{|c|c|c|c|c|}
\hline & Patient 1 & Patient 2 & Patient 3 & Patient 4 \\
\hline Sex & Female & Female & Female & Female \\
\hline Age at diagnosis (years) & 1.2 & 0.5 & 2.7 & 2.8 \\
\hline Age at TCZ initiation (years) & 1.8 & 1.1 & 2.8 & 2.8 \\
\hline $\begin{array}{l}\text { Number of TCZ doses at the } \\
\text { occurrence of anaphylaxis }\end{array}$ & $2^{\text {nd }}$ & $3^{\text {rd }}$ & $10^{\text {th }}$ & $4^{\text {th }}$ \\
\hline Total number of TCZ doses (times) & 6 & 5 & 10 & Continued \\
\hline Dose of GC at TCZ initiation & $\begin{array}{c}\mathrm{PSL} 0.57 \mathrm{mg} / \mathrm{kg} / \\
\text { day }\end{array}$ & $\begin{array}{c}\text { PSL } 1.95 \mathrm{mg} / \mathrm{kg} / \\
\text { day }\end{array}$ & PSL 1.14 mg/kg/day & L-DEX 5 mg/day \\
\hline Symptoms by anaphylaxis & $\begin{array}{l}\text { Tachycardia, } \\
\text { cold extremities, } \\
\text { and urticaria }\end{array}$ & $\begin{array}{l}\text { Tachycardia, } \\
\text { tachypnea, and } \\
\text { vomiting }\end{array}$ & $\begin{array}{l}\text { Fever, tachycardia, } \\
\text { and hypotension }\end{array}$ & $\begin{array}{l}\text { Fever, chills, and } \\
\text { urticaria }\end{array}$ \\
\hline IL-6 levels at TCZ induction (pg/mL) & 71.7 & 6.2 & 1.6 & 255.6 \\
\hline IL-18 levels at TCZ induction (pg/mL) & Unavailable & 70979 & 64200 & 80285 \\
\hline IL-6 levels at anaphylaxis (pg/mL) & 21.6 & $<1.5$ & 4.1 & 23.2 \\
\hline Anti-TCZ IgE/lgG antibody & $-/+$ & $+/+$ & $-/-$ & $+/-$ \\
\hline Continuation of TCZ treatment & No & No & No & Yes \\
\hline \multicolumn{5}{|l|}{ Side effects by GC } \\
\hline Growth impairment & Yes & Yes & Yes & Yes \\
\hline Others & Osteoporosis & $\begin{array}{l}\text { Glaucoma, } \\
\text { cataract }\end{array}$ & None & Osteoporosis \\
\hline
\end{tabular}

of patients with severe rheumatic diseases. TCZ has durable efficacy and good tolerability in long-term treatment for children with sJIA [11]. However, unfortunately, some patients experience a reduced therapeutic response and severe hypersensitivity because of development of ADAs [12-18]. The immunogenicity of biologics is affected by various factors, including molecule-related factors (e.g., mechanisms of action, molecular structure, and manufacturing) and patients' characteristics [10]. Interestingly, a previous study showed that the immunogenicity risk of TCZ was lower than that of anti-tumor necrosis factor- $\alpha$ agents [10]. One possible mechanism of the low immunogenicity of TCZ might be explained by downregulation of $\mathrm{B}$ cell activity via blocking of IL-6 signaling [10]. Furthermore, another study suggested that low immunogenicity of TCZ might be associated with monoclonal antibody structure (e.g., a specific molecular structure with an idiotype) and manufacturing processes [10]. In a phase III Japanese clinical trial of TCZ therapy for patients with sJIA, four of 67 (6.0\%) patients were positive for anti-TCZ antibodies and experienced mild to moderate IRs [11]. Two of them were withdrawn from the trial. In postmarketing surveillance of TCZ for patients with sJIA, a total of $7.2 \% \quad(n=30)$ of patients had IRs and $1.9 \%(\mathrm{n}=8)$ experienced serious IRs [19]. Anti TCZ-antibodies were examined in six of the eight patients and five $(83.3 \%)$ were positive for anti-TCZ antibodies. Additionally, in the TENDER trial, a randomized trial of TCZ for patients with sJIA in Western countries, anti-TCZ antibodies were detected in only two of $112(1.8 \%)$ patients [20]. Consequently, both patients withdrew from the clinical trial. The incidence of IRs in our study is higher than that in the studies mentioned above $[11,19,20]$. The median age of the patients in our study, in those in a phase III Japanese clinical trial, and in those in postmarketing surveillance was 7.2 years (range, 1.1-14.3 years), 8.0 years (range, 2-19 years), and 10.0 years (range, $0-53$ years), respectively $[11,19]$. However, details of age distribution were not shown, except for in our study. Our study may have included a younger population than the previous studies.

Therefore, the incidence of severe IRs in our study could be higher than that of the previous studies $[11,19,20]$. Previous reports have described that patients with early-onset sJIA tend to exhibit a more aggressive and refractory clinical course than those with late-onset sJIA $[21,22]$. The immune system in young children may be skewed to innate immunity rather than acquired immunity compared with older children or adults [21]. Therefore, because innate immunity plays a critical role in the pathogenesis of sJIA, younger patients more frequently 
present with MAS and destructive arthritis than do older patients $[21,23]$. Consequently, blood TCZ concentrations in younger patients may disappear more rapidly than those in older patients. Some previous reports have shown that a considerable decline in blood concentrations of biologics occurs when blood concentrations reach a low threshold [24,25]. Maintaining high blood concentrations of biologics, especially trough levels, are essential for preventing ADAs. Some studies have reported that low blood concentrations of biologics can lead to ADAs [26-30]. A rapid drop in blood concentrations of biologics may accelerate drug clearance and result in development of ADAs.

Drugs can be administered based on three approaches: fixed dosing, body weight (BW)based dosing, or body surface area (BSA)-based dosing [31]. Biologics in adults and children are generally dosed based on BW or BSA. However, the gap in dosage between BSA and BW becomes more apparent in younger children. Yim et al. showed that the BW-based dose of etanercept in patients who weighed $\leq 23 \mathrm{~kg}$ tended to result in lower concentrations compared with patients who weighed $>23 \mathrm{~kg}$ [32]. Additionally, BSAbased dosing is better for adjusting the variability for clearance than BW-based dosing in younger children [32]. In fact, our study showed that the BSA-based dosage in the IR group was less than that in the non-IR group Table 1 . Therefore, BSA-based dosing of biologics may be more suitable than BW-based dosing in younger children. Although the approved dose of TCZ in Japan is $8 \mathrm{mg} / \mathrm{kg}$, TCZ doses in the EU/USA are $12 \mathrm{mg} / \mathrm{kg}$ in children weighing $<30 \mathrm{~kg}$ and $8 \mathrm{mg} / \mathrm{kg}$ in children weighing $\geq 30 \mathrm{~kg}$. A lower dose of TCZ was reported to cause lower efficacy in small children [20]. A lower approved dose may partly explain the high incidence of IRs, especially in younger children.

Once anti-TCZ antibody emerges, continuing TCZ treatment becomes difficult. In two of our patients who presented with severe IRs, we attempted to re-administer TCZ, but both patients could not tolerate TCZ treatment. Fortunately, a clinical trial of canakinumab for patients with sJIA is ongoing in Japan. We are hopeful that canakinumab can be beneficial for these patients after official approval.

\section{Limitations}

There are some limitations to our study, such as a single-center experience, limited sample size, variation of use of GCs among patients, various follow-up durations, and the retrospective design. Additionally, we could not measure the titer of anti-TCZ antibodies and blood TCZ concentrations in our patients, except for four patients who developed severe IRs. Monitoring of blood TCZ concentrations may be helpful for maintaining effective concentrations, and for adjusting appropriate doses and the interval of treatment in each patient.

\section{Conclusion}

In conclusion, severe IRs to TCZ are likely to occur in young patients, especially those younger than 3 years old. The emergence of anti-TCZ antibodies increases the risk of loss of clinical response to TCZ. Induction of TCZ in young patients with sJIA should be carefully observed and we need to reconsider the optimal regimen of treatment.

\section{Acknowledgement}

We thank Ms. Mayuko Miyake for her technical assistance. We thank Ellen Knapp, PhD, from Edanz Group (www.edanzediting.com/ac) for editing a draft of this manuscript.

Disclosure/Conflict of Interest

All authors disclose no conflicts of interest regarding the publication of this manuscript.

\section{References}

1. Petty RE, Southwood TR, Manners P et al. International league of associations for rheumatology classification of juvenile idiopathic arthritis: second revision, Edmonton 2001. J. Rheumatol. 31(2), 390-2 (2004).

2. Yokota S. Juvenile rheumatoid arthritis. Nihon. Rinsho. 63(5), 274-80 (2005).

3. Ravelli A, Martini A. Juvenile idiopathic arthritis. Lancet. 369(9563), 767-78 (2007).

4. Minden K, Kiessling U, Listing J et al. Prognosis of patients with juvenile chronic arthritis and juvenile spondyloarthropathy. J Rheumatol. 27(9), 2256-63 (2000).

5. Fantini F, Gerloni V, Gattinara M et al. Remission in juvenile chronic arthritis: a cohort study of 683 consecutive cases with a mean 10 year followup. J. Rheumatol. 30(3), 579-84 (2003).

6. Otten $\mathrm{MH}$, Anink J, Prince $\mathrm{FH}$ et al. Trends in prescription of biological agents and outcomes of juvenile idiopathic arthritis: results of the Dutch national Arthritis and Biologics in Children Register. Ann. Rheum. Dis. 74(2), 1379-86 (2015).

7. Nishimoto N, Terao K, Mima T et al. Mechanisms and pathologic significances in increase in serum interleukin-6 (IL-6) and soluble IL-6 receptor after administration of an anti-IL-6 receptor antibody, tocilizumab, in patients with rheumatoid arthritis and Castleman disease. Blood. 112(10), 3959-64 (2008). 
8. Fujimoto $\mathrm{K}$, Ida $\mathrm{H}$, Hirota $\mathrm{Y}$ et al. Intracellular Dynamics and Fate of a Humanized Anti-Interleukin-6 Receptor Monoclonal Antibody, Tocilizumab. Mol. Pharmacol. 88(4), 660-75 (2015).

9. Stubenrauch K, Wessels U, Birnboeck H et al. Subset analysis of patients experiencing clinical events of a potentially immunogenic nature in the pivotal clinical trials of tocilizumab for rheumatoid arthritis: Evaluation of an antidrug antibody ELISA using clinical adverse event-driven immunogenicity testing. Clin. Ther. 32(9), 1597-609 (2010).

10. Burmester GR, Choy E, Kivitz A et al. Low immunogenicity of tocilizumab in patients with rheumatoid arthritis. Ann. Rheum. Dis. 76(6), 1078-85 (2017).

11. Yokota S, Imagawa T, Mori M et al. Longterm safety and effectiveness of the anti-interleukin 6 receptor monoclonal antibody tocilizumab in patients with systemic juvenile idiopathic arthritis in Japan. J. Rheumatol. 41(4), 759-67 (2014).

12. Wolbink GJ, Aarden LA, Dijkmans BA. Dealing with immunogenicity of biologicals: assessment and clinical relevance. Curr. Opin. Rheumatol. 21(3), 211-5 (2009).

13. Schellekens H. Immunogenicity of therapeutic proteins: clinical implications and future prospects. Clin. Ther. 24(11), 1720-40 (2002).

14. Puxeddu I, Caltran E, Rocchi V et al. Hypersensitivity reactions during treatment with biological agents. Clin. Exp. Rheumatol. 34, 129-32 (2016).

15. Emi Aikawa N, de Carvalho JF, Artur Almeida Silva $\mathrm{C}$ et al. Immunogenicity of Anti-TNF-alpha agents in autoimmune diseases. Clin. Rev. Allergy. Immunol. 38(23), 82-9 (2010).

16. Anderson PJ. Tumor necrosis factor inhibitors: clinical implications of their different immunogenicity profiles. Semin. Arthritis. Rheum. 34(5 Suppl 1), 19-22 (2005).

17. Bartelds GM, Krieckaert CL, Nurmohamed MT et al. Development of antidrug antibodies against adalimumab and association with disease activity and treatment failure during long-term follow-up. JAMA. 305(14), 1460-8 (2011).

18. Radstake TR, Svenson M, Eijsbouts AM et al. Formation of antibodies against infliximab and adalimumab strongly correlates with functional drug levels and clinical responses in rheumatoid arthritis. Ann. Rheum Dis. 68(11), 1739-45 (2009).

19. Yokota S, Itoh Y, Morio T et al. Tocilizumab in systemic juvenile idiopathic arthritis in a real-world clinical setting: results from 1 year of postmarketing surveillance follow-up of 417 patients in Japan. Ann. Rheum. Dis. 75(9), 1654-60 (2016).

20. De Benedetti F, Brunner HI, Ruperto N et al. Randomized trial of tocilizumab in systemic juvenile idiopathic arthritis. N. Engl. J. Med. 367(25), 2385-95 (2012).
21. Russo RA, Katsicas MM. Patients with very earlyonset systemic juvenile idiopathic arthritis exhibit more inflammatory features and a worse outcome. J. Rheumatol. 40(3), 329-34 (2013).

22. Spiegel LR, Schneider R, Lang BA et al. Early predictors of poor functional outcome in systemic-onset juvenile rheumatoid arthritis: a multicenter cohort study. Arthritis. Rheum. 43(11), 2402-9 (2000).

23. Mellins ED, Macaubas C, Grom AA. Pathogenesis of systemic juvenile idiopathic arthritis: some answers, more questions. Nat. Rev. Rheumatol. 7(7), 416-26 (2011).

24. Loyet KM, Deng R, Liang WC et al. Technology comparisons for anti-therapeutic antibody and neutralizing antibody assays in the context of an antiTNF pharmacokinetic study. J. Immunol. Methods. 345(1-2), 17-28 (2009).

25. Brandse JF, van den Brink GR, Wildenberg ME et al. Loss of Infliximab into Feces Is Associated with Lack of Response to Therapy in Patients With Severe Ulcerative Colitis. Gastroenterology. 149(2), 350-5. e2 (2015).

26. Vermeire S, Noman M, Van Assche G et al. Effectiveness of concomitant immunosuppressive therapy in suppressing the formation of antibodies to infliximab in Crohn's disease. Gut. 56(9), 1226-31 (2007).

27. Metsios GS, Stavropoulos-Kalinoglou A, Douglas $\mathrm{KM}$ et al. Blockade of tumour necrosis factor-alpha in rheumatoid arthritis: effects on components of rheumatoid cachexia. Rheumatology (Oxford). 46(12), 1824-7 (2007).

28. van den Bemt BJ, den Broeder AA, Wolbink GJ et al. Anti-infliximab antibodies are already detectable in most patients with rheumatoid arthritis halfway through an infusion cycle: an open-label pharmacokinetic cohort study. BMC. Musculoskelet. Disord. 12, 12 (2011).

29. Nanda KS, Cheifetz AS, Moss AC. Impact of antibodies to infliximab on clinical outcomes and serum infliximab levels in patients with inflammatory bowel disease (IBD): a meta-analysis. Am. J. Gastroenterol. 108(1), 40-7 (2013).

30. Vande Casteele N, Gils A. Pharmacokinetics of anti-TNF monoclonal antibodies in inflammatory bowel disease: Adding value to current practice. J. Clin. Pharmacol. 55 (Suppl 3), S39-50 (2015).

31. Pai MP. Drug dosing based on weight and body surface area: mathematical assumptions and limitations in obese adults. Pharmacotherapy. 32(9), 856-68 (2012).

32. Yim DS, Zhou H, Buckwalter $M$ et al. Population pharmacokinetic analysis and simulation of the timeconcentration profile of etanercept in pediatric patients with juvenile rheumatoid arthritis. J. Clin. Pharmacol. 45(3), 246-56 (2005). 